\title{
A Study of Performance Management System as a Strategic Tool of HRM
}

\author{
Ashwini Walhekar ${ }^{1 *}$, Anita Khatke ${ }^{2}$ \\ ${ }^{1}$ Research Scholar, Nevile Wadia Institute of Management Studies and Research, Pune, India \\ ${ }^{2}$ Director, Jaywantrao Sawant Institute of Management and Research, Pune, India \\ *Corresponding author: ashwinikakade27@gmail.com
}

\begin{abstract}
In present hard-hitting competition, one of the strategies to be a successful organization is to get right candidates for every available position in the organization and retain the good employees to have better and highly motivated workforce. So what actually needed for an organization and managers is to attract, retain and motivate a talented workforce? It is proven fact that all high performance organizations whether public or private are and must be focus on developing and adopting effective performance measurement and performance management system; because it is only with the help of these systems organization can remain high performer. Now-a-days, in any industry whether small or big, human resource management not just plays traditional role but they are using various strategical tools of HRM to evaluate its employees' performance and manage it accurately with a new system in the field of HRM known as Performance Management System (PMS). PMS helps the organization in aligning individual's goal and objectives with organizational objectives. This paper deals with how PMS can be utilized for taking various strategic HR decisions and the effectiveness of PMS. The result of the study shows that a performance management system acts as a strategic tool and a powerful foundation for the employees to achieve their ambitions and organizations to achieve their key financial goals.
\end{abstract}

Keywords: Human Resource Management, Performance, Performance Management System (PMS).

\section{Introduction}

In the present days of cut throat competition due to liberalization and globalization of world economy organizations have realized the need for adopting strategic HRM tools to remain ahead in this competitive world. An effective performance management system plays a crucial role in assessing and developing the performance of the employees in an organization for achieving corporate objectives and goals. Performance management system is a key HR function for aligning all major HR functions and sub-functions of the organization so that the focus remains only on achieving organizational objectives. Performance management is a process of planning performance, appraising and evaluating performance, feedback and counseling of every employee and developing their performance for achieving individual and organizational objectives. The biggest challenge faced by every HR manager today is managing employee performance within an organization. Bringing out best from each and every employee is the ultimate goal of HRM.

Most of the organizations see performance management system as an important strategic tool to remain ahead in this competitive world. Because performance management system helps employees to know exactly what is expected from them and assure immediate supervisor and HR manager that employees goals are aligned with the organization's goals. As the world has become global village maintaining employee's performance with $100 \%$ efficiency has become a major challenge for every organization, in one or the other way.

\section{Objectives of the Study}

Following are the objectives of the study:

1. To highlight the importance, role and characteristics of Performance Management System.

2. To study the PMS as a Strategic tool of HRM.

\section{Need of the Study}

Human Resource is the real resource for any organization. All other resources in the organization are utilized by human resource and so fullest utilization of all resources depends on employee performance of the organization. Today the globalization of the world economy and several other factors are again generating changes in how organizations organize, manage and use their Human Resource. Technology is also changing the nature of work. Knowledge-intensive techniques, industrial automation, reengineering with optimum utilization of resources sets the current working environment. To add to this the personal life of the individual employees also affect his professional work, aims \& ambitions and decisions. Hence managing employee's performance continuously is becoming critical to the policies and planning of the top management.

Performance management has attracted the attention of all organizations as the information provided by PMS can be utilized for taking various important HR decisions related to Human Resource Planning, Recruitment and selection, Training and Development, compensation Management, career planning, talent management, performance based pay etc. 


\section{Research Methodology Used in the Present Study}

Secondary data were used for the present study. The secondary data were collected from the various research publications, books, journals, magazines and bulletin etc.

\section{Meaning and Definition of Performance Management System}

Performance management is a process of planning performance, appraising performance, giving its feedback and counseling an employee to improve its performance. Thus, performance management involves different activities,

Planning Performance - that is what an employee is expected to achieve with a set of given resources and within a time frame.

Performance Appraisal - appraisal whether the given result has been received or not

Performance Feedback - giving feedback to the employee concerned about where he lacks, its reason

Counseling - counsel him how he can improve his performance

\section{Definitions:}

According to Armstrong "Performance Management is a means of getting better results from the organization, teams, and individuals by understanding and managing performance within an agreed framework of planned goals standards and competence requirements".

Armstrong and Baron have defined performance management as follows:

"Performance management is a process that contributes to the effective management of individuals and teams to achieve high levels of organizational performance. As such, it establishes shared understanding about what is to be achieved and an approach to leading and developing people which will ensure that it is achieved."

The specific uses and importance of performance management are,

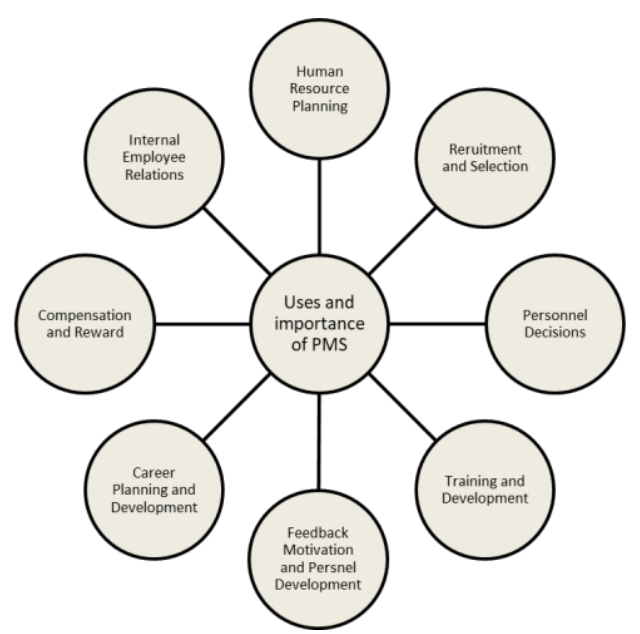

Fig. 1. Uses and importance of performance management system

Benefits of good performance management system to organization, managers and employees:
A. Organization

- Improves overall productivity of the organization.

- Attract and retain best talent within an organization.

- Sets clear responsibilities and accountabilities for each employee.

- Facilitates two way communications within an organization.

- Facilitates strategic HR decisions.

B. Managers

- Managers can focus on important strategic work as PMS will take care of routine work.

- Reduces conflicts within an organization as every important HR decision will have support of transparent PMS data.

- Increases efficiency of team members and motivates them to perform better consistently

- Improves moral and motivation of the employees

- Improves communication between managers and employees.

C. Employees

- Clarity about expectations from an employee and key responsibility areas (KRAs).

- Provides self-assessment and recognize strengths and weaknesses.

- Attainment of full potential and creates a work-life balance.

- Enhance the productivity and performance of employees.

- Career development and career growth for an employee which results in job satisfaction.

\section{Literature Review}

Various researches have been conducted in the field of performance management system. Few are discussed in the present study.

According to Roberts (2001), PMS is a process which has 4 important steps:

Planning Performance - what an employee is expected to achieve within a given time frame and resources.

Performance Appraisal - appraisal whether the given result has been received or not

Performance Feedback - giving feedback to the employee about his performance.

Counseling - counsel employee about his performance and try to find out the reason for his poor performance

Helm et al. (2007) says that PMS is important tool to improve an organization's performance; it facilitates the organization to achieve its goals and objective. It can develop a performance oriented culture within the organization. It helps the individual employee to have the clarity about what exactly is expected from him as there will be proper performance planning of each employee. PMS can also identify talented 
individuals for promotion and it also establishes linkage between pay and performance. It means various important HR decisions can be accurately taken with the help of PMS.

Bhattacharjee and Sengupta (2011) emphasized in their study that employees are the most crucial and valuable assets of an organization. If an organization wants to gain competitive advantages, it is very important to bridge the gap between the actual competence of human resource working in the organization and the desired competence expected from them. It is with the help of well-established Performance management system the organization can bridge this gap between actual performance and expected performance.

Sunil Kumar Pradhan and Dr. Suman Kalyan Chaudhury (2012), This study found that the main objective of performance management system is to align the individual and organizational goals in such a way that to give best possible platform to the employees to perform with $100 \%$ efficiency which will lead to organizational development, employee satisfaction and increased employee retention.

\section{Performance Management System as a Strategic Tool}

Organizations have realized the significance of adopting strategic HR practices for gaining a competitive edge over the competitors.

A well designed effective performance management system can play a vital role in aligning the actions of the employees in an organization for recognizing the crucial corporate goals. Performance management is a useful tool for aligning all the major organizational functions and sub functions so that the focus is directed towards attainment of the organizational goal. By clearly explaining both the individual and team responsibilities in the form of Key Responsibility Areas (KRAs) as well as by creating an understanding of shared responsibilities, a good performance management system smoothens the progress and development of employees.

Performance Management system can definitely be used as an important Strategic tool of HRM, as crucial Strategic HR decisions related to Human Resource Planning, Recruitment and Selection, Training and Development, Compensation and Pay Structure, Promotion, Transfer, career Planning can be accurately taken with the help of PMS.

Performance Management System is the vital key in Human Resource Management (HRM). PMS is a crucial business driver that helps to achieve business result.

\section{Conclusion}

With this study it can be said that Performance Management System is the important strategic tool of Human Resource management. A well designed PMS can help the organization to maximize employee performance and encourage organizational climate of trust, collaboration, communication, team work etc. It is important for an organization to have such system which not only identify to high performer but also help poor performer to improve his performance with well-designed Training program and personalized counseling. The performance management system is the strategic tool that can be used to transform people's talent and motivation into a strategic business advantage.

\section{References}

[1] Armstrong, M \& Baron, A, (2004), "Managing Performance: Performance Management in Action," CIPD, London.

[2] Singh, B.D. (2010), "Performance Management Systems: A Holistic Approach", India Excel Books.

[3] T.V. Rao (2007), "Performance Management and Appraisal Systems HR tool for Global Competitiveness" Sage publication ltd.

[4] Bhattacharjee S., and Sengupta S., "A study of performance Management System in a Corporate Firm”, VSRD-IJBMR 1(8) (2011) 496-513.

[5] Roberts, I. (2001). "Reward and performance management, Human resource management: A contemporary approach" (3rd edn.). Edinburgh Pearson.

[6] Sunil Kumar Pradhan, Suman Kalyan Chaudhury. (2012) "A survey on employee performance management and its implication to their relation in OCL India Ltd", Asian Journal of Research in Social Sciences and Humanities. 